\title{
CARBONO, CARBONO DA BIOMASSA MICROBIANA E ATIVIDADE ENZIMÁTICA EM UM SOLO SOB MATA NATURAL, PASTAGEM E CULTURA DO ALGODOEIRO(1)
}

\author{
M. MARCHIORI J ÚNIOR ${ }^{(2)} \&$ W. J . MELO(3)
}

\begin{abstract}
RESUMO
Avaliaram-se os parâmetros $\mathrm{C}_{\text {orgânicor }} \mathrm{C}_{\text {microbiano, }}$ atividades de celulase $\mathrm{e}$ amilase em amostras de uma Terra Roxa Estruturada sob mata natural (MN),

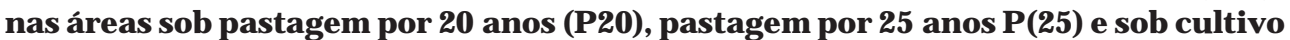
do algodoeiro por 10 anos (A10), obtidas no verão nas profundidades de 0-10, 10-20 e 20-30 cm. Os teores de $C_{\text {orgânico, }} C_{\text {microbiano }} e$ as atividades de amilase $e$ celulase foram muito semel hantes entre MN e nas áreas P20 e P25. Somente foi observada redução em $18 \%$ do $C_{\text {orgânico }}$ da $\mathrm{P} 25$, em relação à $\mathrm{MN}$, na profundidade de $0-10 \mathrm{~cm}$. $O$ cultivo convencional do algodoeiro por 10 anos provocou reduções de 54 a $81 \%$, em relação à $M N$, no $C_{\text {microbiano e na atividade de amilase nas três }}$ profundidades de amostragem, assim como apresentou valor da relação $\mathrm{C}_{\text {microbiano }} / \mathrm{C}_{\text {orgânico }}$ menor que $1,0 \%$, indicando redução na dinâmica da matéria orgânica do solo. $0 \mathrm{C}_{\text {microbiano }} \mathrm{e}$ as atividades de amilase e celulase correlacionaram-se positiva e significativamente nas três profundidades,

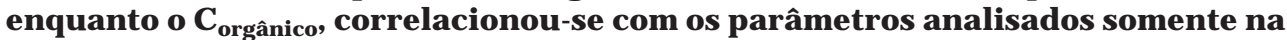
profundidade de $0-10 \mathrm{~cm}$.
\end{abstract}

Termos de indexação: manejo do solo, celulase, amilase, matéria orgânica, uso do solo, enzimologia.

(1) Parte da Tese de Mestrado do primeiro autor, apresentada ao Curso de Pós-Graduação em Agronomia, área de concentração em Produção Vegetal, Faculdade de Ciências Agrárias e Veterinária - FCAV/UNESP, e apresentado, na forma de resumo, no XXVI Congresso Brasileiro de Ciência do Solo. Recebido para publicação em março de 1998 e aprovado em janeiro de 1999.

(2) Aluno de Pós-Graduação da FCAV/UNESP. Rodovia Carlos Tonanni, Km 5, CEP 14870-000 J aboticabal (SP). Bol sista da FAPESP.

(3) Professor do Departamento de Tecnologia da FCAV/UNESP. 


\title{
SUMMARY: CARBON, MICROBIAL BIOMASS CARBON AND ENZYME ACTIVITY OF A SOIL UNDER NATURAL FOREST, GRASSLAND AND COTTON CULTURE
}

\begin{abstract}
This work was carried out to evaluatethealterations in organic-C, mi crobial-C and in theactivities of theenzymes cel lul aseand amylasein soil samples of a Rhodustal $\mathrm{f}$ coll lected in thesummer at 0-10, 10-20 and 20-30 cm depths, under natural forest (NF), 20 (P20) and 25 (P25) year old pastures and 10 year old cotton cultivation. Organic-C and microbial-C contents and the amylase and cellulase activities were very similar in NF, P20 and P25. Reduction of $18 \%$ in organic-C was observed in P25, when compared to NF at the depth of $0-10 \mathrm{~cm}$. The conventional cultivation of cotton for 10 years caused reductions from 54 to $81 \%$ in microbial-C and in the activity of amylase in relation to NF, in the threesampling depths, presenting a mi crobial-C/ organic-C ratio smaller than $1.0 \%$, which suggests reduced organic matter dynamics. Microbial-C was positivel y correl ated to amyl ase and cel lulase activities at thethreedepths, but theorganic- $\mathrm{C}$ was only corre lated to theanalyzed parameters at the $0-10 \mathrm{~cm}$ depth.
\end{abstract}

Index terms: soil management, cellulase, amyl ase, enzymology, organic matter, soil use.

\section{NTRODUÇÃO}

Os organismos do solo interagem intensamente com as partículas do solo e são responsáveis por inúmeros processos biológicos e bioquímicos essenciais para garantir a sustentação do ecossistema onde el es vivem.

Atualmente, a biomassa microbiana, respiração e atividade enzimática, geral ou específica do solo, podem ser usadas como indicativos da qualidade do solo (Campbell et al., 1992; Doran et al., 1994).

Define-se biomassa microbiana do solo (BMS) como a parte viva da matéria orgânica do solo, excluindo raízes e animais maiores do que, aproximadamente, $5.000 \mu \mathrm{m}^{3}$. Operacional mente, atua como agente de transformação da matéria orgânica no ciclo de nutrientes e no fluxo de energia (J enkinson \& Ladd, 1981; Wardle, 1992).

Como resultado da atividade dos microrganismos, ocorre a produção de várias enzimas extracelulares, capazes deatacar substratos orgâni cos que compõem a matéria orgânica do solo ou necromassa, liberando monômeros, quesão absorvidos e metabolizados nas células, produzindo biomassa, $\mathrm{CO}_{2}, \mathrm{H}_{2} \mathrm{O}$ e el ementos minerais (Stevenson, 1986)

A utilização de métodos convencionais de preparo do solo, associados a culturas anuais, normalmente provoca redução nos teores de carbono orgânico no solo, resultante do aumento da taxa de decomposi ção anual ou redução da taxa de adição de material orgânico (Dalal \& Mayer, 1986a, b). Segundo J enkinson \& Rayner (1977) e Powlson et al. (1987), a BMS parece mais sensível a mudanças iniciais no conteúdo de matéria orgânica do solo.
Modificações mensuráveis na BMS têm sido detectadas em função das práticas de preparo do solo, do manejo de plantas e da adubação. A derrubada da mata tropical, seguida da queima da vegetação, provoca uma queda inicial, com posterior el evação no nível de BMS, determinando, ainda, uma nova distribuição ao longo do perfil (Cerri et al., 1985; Geraldes et al., 1995).

As alterações na BMS podem ser anal isadas pela relação carbono mi crobiano/carbono orgânico do sol o. Tal relação expressa o tamanho do compartimento carbono microbiano em relação ao compartimento carbono orgânico do sol o. Anderson \& Domsch (1989) encontraram valores de $2,3 \%$, para monoculturas, e 2,9\%, para sistemas em rotação de culturas.

Ainda existem poucas informações sobre mudanças nas propriedades bioquímicas e biológicas do solo ao se substituir a floresta natural por pastagem ou culturas anuais em regiões sob clima tropical.

O objetivo deste trabalho foi verificar as alterações nos teores de $\mathrm{C}_{\text {orgânico, }} \mathrm{C}_{\text {microbiano, }}$ atividades de celulase e de amilase em um solo de alta fertilidade natural mantido sob pastagem por 20 anos, pastagem por 25 anos eal godão por 10 anos, em relação ao mesmo solo sob mata natural.

\section{MATERIAL E MÉTODOS}

Solo - As amostras de solo foram coletadas em uma unidade de sol o pertencente ao grupo de Terra Roxa Estruturada (Rhodustalfs), situada no 
município dePaulo deFaria (SP), Brasil. O clima da região foi classificado como Cwa, segundo Köppen, com inverno seco. A análise granul ométrica revel ou, na profundidade de $0-20 \mathrm{~cm}$ : argila $=450 \mathrm{~g} \mathrm{~kg}^{-1}$; silte $=320 \mathrm{~g} \mathrm{~kg}^{-1}$; areia fina $=180 \mathrm{~g} \mathrm{~kg}^{-1}$, e areia grossa $=$ $50 \mathrm{~g} \mathrm{~kg}^{-1}$. Os resultados da análise de fertilidade, segundo métodos IAC (1996), encontram-se no quadro 1.

Descrição das áreas - Os tratamentos foram definidos segundo os tipos de uso dosolo. Escol heramse quatro áreas com aproximadamente 4 ha cada (uma para cada tipo de uso), distribuídas numa faixa homogênea de sol o com aproximadamente 30 ha. Os tipos de uso do solo analisados foram: MN (mata natural); P20 (pastagem por 20 anos; a mata natural foi removida em 1972, seguindo-se manejo com fogo no anos de 1973 e 1974 e instalação de pastagem com capim-col onião- Panicum maxi mum em 1975); P25 (pastagem por 25 anos; a mata natural foi removida em 1966, seguindo-se pousio e manejo com fogo até 1970, quando se formou pastagem com capim-colonião que, em 1991, foi substituído por capim-braquiária - Brachiaria decumbens), e A10 (algodão por 10 anos; a mata natural foi removida em 1985, seguindo-se cultivo anual de algodoeiro Gossi pi um hirsutum). Nas áreas sob pastagens, não foram feitas calagens e adubações. $\mathrm{Na}$ área com algodoeiro, durante o preparo do solo, foram feitas calagens, na dose de $3 \mathrm{Mg} \mathrm{ha}^{-1}$, a cada 4 anos; nos plantios, foram aplicados $400 \mathrm{~kg} \mathrm{ha}^{-1} \mathrm{da}$ fórmula 315-10 e, em cobertura, $40 \mathrm{~kg}$ ha-1 de N (na forma de sulfato de amônio) e $20 \mathrm{~kg} \mathrm{ha}^{-1} \operatorname{de~}_{2} \mathrm{O}$ (na forma de cloreto de potássio).

Delineamento experimental - Fez-se uso do del ineamento intei ramente casual izado, com quatro repetições. Os dados foram anal isados em esquema de parcelas subdivididas, em que os tratamentos principais foram constituídos pelos tipos de uso do solo (4) e os tratamentos secundários, pelas três profundidades de amostragem. Após análise de variância, aplicou-se o teste de Tukey, a 5\% para comparação das médias.
Amostragem - Foi realizada no dia 03/02/96. Para cada tipo de uso do solo, foram delimitadas quatro parcelas com, aproximadamente, 1 ha. Em cada uma delas, foram col hidas, por caminhamento em ziguezague dentro da área útil da parcela, 20 amostras simples nas profundidades de 0-10, 10-20 e20-30 cm, as quais foram reunidas, deacordo comas profundidades, para formarem as amostras compostas. No caso da área cultivada com algodoeiro, as amostras foram obtidas nas entrelinhas da cultura.

Preparo das amostras - As amostras de solo foram acondicionadas em sacos de polietileno e mantidas em gel o. Nolaboratório, foi imediatamente retirada uma subamostra para avaliação da biomassa microbiana, real izada no prazo máximo de 2 dias. O material restante foi estendido para secagem ao ar por $48 \mathrm{~h}$ e passado por peneira com malha de $2 \mathrm{~mm}$ (TFSA).

Determinações nas amostras de solo - O teor de $C_{\text {orgânico }}$ foi avaliado pel o método da oxidação por via úmida (dicromato de potássio em meio de ácido sulfúrico concentrado), determinando-se o excesso de di cromato por titulação com sol ução de sul fato ferroso amoniacal previamente padronizada (Dabin, 1976).

O $\mathrm{C}_{\text {microbiano foi determinado pelo método da }}$ fumigação extração (Vance et al., 1987), que consiste em se destruir a membrana celular dos microrganismos com clorofórmio, seguindo-se a extração do carbono liberado por uma solução de sulfato de potássio, o qual foi determinado pelo método da oxidação por via úmida.

Calculou-sea relação $C_{\text {microbiand }} / C_{\text {orgânico, expressa }}$ em percentagem, utilizando-se a seguinte fórmula $\left(\mathrm{C}_{\text {microbiano}} / \mathrm{C}_{\text {orgânico }}\right) \times 100$.

A atividade da cel ulase foi cal culada pel o método de Pancholy \& Rice (1973) e a atividade da amilase pel o método de Ross (1965). Tais métodos consistem em incubar amostras de solo na presença de um substrato específico, carboximetilcel ul ose e amido, respectivamente, sob condições controladas, seguindo-se a determinação da quantidade de açúcares redutores formados.

\section{Quadro 1. Análise de fertilidade de uma amostra de Terra Roxa Estruturada sob diferentes tipos de uso (profundidade de 0-20 cm)}

\begin{tabular}{|c|c|c|c|c|c|c|c|c|c|c|}
\hline Área & $\begin{array}{c}\mathbf{P} \\
\text { resina }\end{array}$ & M.O. & $\begin{array}{c}\text { pH } \\
\mathrm{CaCl}_{2}\end{array}$ & $\mathbf{K}$ & $\mathbf{C a}$ & Mg & $\mathbf{H}+\mathbf{A I}$ & SB & СТC & $\mathbf{v}$ \\
\hline & $\mathrm{mg} \mathrm{dm}^{-3}$ & $\mathrm{~g} \mathrm{~kg}^{-1}$ & & 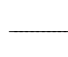 & 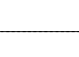 & $-\mathrm{mm}$ & ${ }_{c} d^{-3}$ & & & $\%$ \\
\hline Mata (natural) & 6 & 40 & 5,7 & 4,9 & 83 & 26 & 28 & 113,9 & 141,9 & 80 \\
\hline Pastagem (20 anos) & 7 & 40 & 5,8 & 5,5 & 93 & 26 & 22 & 124,5 & 146,5 & 85 \\
\hline Pastagem (25 anos) & 5 & 39 & 5,8 & 7,5 & 68 & 28 & 22 & 103,5 & 125,5 & 82 \\
\hline Algodão (10 anos) & 21 & 32 & 6,4 & 9,5 & 190 & 20 & 13 & 219,5 & 232,5 & 94 \\
\hline
\end{tabular}




\section{RESULTADOS E DISCUSSÃO}

Carbono orgânico no solo - O teor de $\mathrm{C}_{\text {orgânico }}$ foi afetado de modo significativo pel o tipo de uso de solo e pela profundidade de amostragem (Quadro 2). No entanto, apenas para a profundidade de $0-10 \mathrm{~cm}$ houve diferença significativa entre os usos do solo, sendo os valores mais el evados observados em MN, e os menores, em A10. Os solos sob P20 e P25 não diferiram entresi quantoaoteor de $C_{\text {orgânico. Segundo }}$ Stevenson (1982), a diminuição do teor de matéria orgânica no sol o sob cultivo não se deve unicamente à redução da quantidade de resíduos adicionados, mas também ao aumento da atividade microbiana, causada por melhores condições de aeração, temperaturas mais elevadas e alternâncias mais freqüentes de umedecimento e secagem do solo. A pastagem por 25 anos e a cultura do al godoei ro por 10 anos reduziram em 18 e $34 \%$, respectivamente, o teor de $\mathrm{C}_{\text {orgânico, em relação à mata natural, na }}$ profundidade de 0-10 cm (Quadro 2).

Num estudo da dinâmica da matéria orgânica em solos sob pastagem após dois e oito anos de implantação, em comparação com a mata natural, Cerri (1989) encontrou que, após dois anos da derrubada da floresta, os teores de C originais diminuíram $25 \%$ na camada superficial. Por outro lado, após oito anos sob pastagem, o solo recuperou os teores totais originais de C, sendo $45,8 \%$ do total representado pelo carbono oriundo da pastagem. Um solo (Entisol) mantido sob gramínea natural e cultivado com milho por 40 anos apresentou diferença de $70 \%$ entre os usos do solo com relação ao teor de $C_{\text {orgânico }}$ (Riffaldi et al., 1994).

Pode-senotar, num sol o de boa fertilidade natural, que a pastagem tende a manter uma condição semel hante à da mata natural com o decorrer do tempo quanto ao teor de $\mathrm{C}_{\text {orgânico. }}$ I sto tem sido

Quadro 2. Teores de $\mathrm{C}_{\text {orgânico }}$ de amostras de Terra Roxa Estruturada sob diferentes tipos de uso e em diferentes profundidades

\begin{tabular}{llll}
\hline \multirow{2}{*}{ Uso do solo } & \multicolumn{3}{c}{ Profundidade (cm) } \\
\cline { 2 - 4 } & \multicolumn{1}{c}{$\mathbf{0 - 1 0}$} & $\mathbf{1 0 - 2 0}$ & $\mathbf{2 0 - 3 0}$ \\
\hline & \multicolumn{3}{c}{$\mathrm{g} \mathrm{kg}^{-1} \mathrm{de} \mathrm{C} \mathrm{na} \mathrm{TFSA}$} \\
Mata (natural) & $23,5 \mathrm{Aa}$ & $15,3 \mathrm{Ba}$ & $13,8 \mathrm{Ba}$ \\
Pastagem (20 anos) & $22,6 \mathrm{Aab}$ & $17,1 \mathrm{Ba}$ & $14,1 \mathrm{Ca}$ \\
Pastagem (25 anos) & $19,2 \mathrm{Abc}$ & $13,6 \mathrm{Ba}$ & $11,8 \mathrm{Ba}$ \\
Algodão (10 anos) & $15,6 \mathrm{Ac}$ & $15,7 \mathrm{Aa}$ & $11,2 \mathrm{Ba}$ \\
\hline
\end{tabular}

Coeficiente de variação para tratamentos $=17,4 \%$, profundidade =9,29; TFSA = terra fina seca ao ar; médias seguidas da mesma letra não diferem significativamente pel o teste de Tukey a $5 \%$; letras minúsculas comparam médias na vertical; letras maiúsculas comparam médias na horizontal. atribuído a um sistema radicular bem desenvolvido e distribuído nos sol os sob pastagem. Para Teixeira \& Bastos (1989), a pastagem, em geral, revela boa distribuição do sistema radicular até um metro de profundidade, com $46,2 \%$ das raízes na camada superficial do solo $(0-10 \mathrm{~cm}), 18,6 \%$ na camada de $10-20 \mathrm{~cm}, 22,8 \%$ na camada de $20-40 \mathrm{~cm}$, e $12,4 \%$ na camada de $40-100 \mathrm{~cm}$.

$\mathrm{Na}$ área de cultivo com algodoeiro, não foram observadas diferenças no teor de $\mathrm{C}_{\text {orgânico }}$ entre as profundidades de 0-10 e $10-20 \mathrm{~cm}$, indicando que não houve estratificação no teor de carbono, como na mata natural e nas pastagens, fato também observado por Angers et al. (1993), comparando um solo não movimentado com um solo arado. Tais autores observaram que, nos solos arados, não ocorreu estratificação do carbono, como em sol o sob floresta.

No geral, houve poucas alterações nos teores de

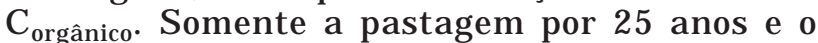
algodoeiro por 10 anos causaram reduções em relação à mata natural na profundidade de $0-10 \mathrm{~cm}$, ou seja, na camada mais sujeita às agressões provocadas pel o manejo. Essa resistência do solo às alterações pode ser conseqüência do alto teor de matéria orgânica e de argila, em que parte da matéria orgânica, ou substâncias húmicas, pode formar complexos organominerais dealta resistência e, portanto, com certo grau de estabilidade, proporcionando ao solo maior resistência à perda de matéria orgânica (Stevenson, 1986).

Carbono da biomassa microbiana - Os teores

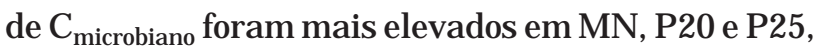
não havendo diferença significativa entre estes. $\mathrm{O}$ único uso do solo que apresentou menor teor de

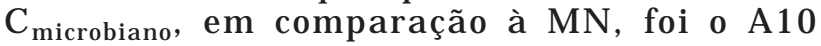
(Quadro 3).
Quadro 3. Teores de $C_{\text {microbino }}$ de amostras de Terra Roxa Estruturada sob diferentes tipos de uso e em diferentes profundidades

\begin{tabular}{|c|c|c|c|}
\hline \multirow{2}{*}{ U so do solo } & \multicolumn{3}{|c|}{ Profundidade $(\mathrm{cm})$} \\
\hline & 0-10 & $10-20$ & 20-30 \\
\hline & \multicolumn{3}{|c|}{$\mathrm{mg} \mathrm{kg}^{-1}$ de $\mathrm{C}$ na TFSE } \\
\hline Mata (natural) & $428 \mathrm{Aa}$ & $324 \mathrm{Ba}$ & $273 \mathrm{Ba}$ \\
\hline Pastagem (20 anos) & $363 \mathrm{Aa}$ & $247 \mathrm{Ba}$ & $226 \mathrm{Ba}$ \\
\hline Pastagem (25 anos) & $402 \mathrm{Aa}$ & $374 \mathrm{Ba}$ & $306 \mathrm{Ba}$ \\
\hline Algodão (10 anos) & $143 \mathrm{Ab}$ & $123 \mathrm{Bb}$ & $95 \mathrm{Bb}$ \\
\hline
\end{tabular}

Coeficiente de variação para tratamentos $=29,8 \%$, profundidade $=26,3 ;$ TFSE =terra fina seca em estufa; médias seguidas da mesma letra não diferem significativamente pelo teste de Tukey a 5\%; letras minúsculas comparam médias na vertical; letras maiúsculas comparam médias na horizontal. 
Não se detectou diferença significativa entreP20, $\mathrm{P} 25$ e MN. Isto pode estar relacionado com o fato de esse sol o ser dealta fertilidade natural (Quadro 1) e as pastagens apresentarem sistema radicular abundante e ativo durante o ano todo, uma vez que, na profundidade de $0-30 \mathrm{~cm}$, concentram-se mais de $60 \%$ do sistema radicular das pastagens. Na área A10, observaram-se reduções de 67, 62 e 65\%, em comparação à $\mathrm{MN}$, para as profundidades de 0-10, 10-20 e 20-30 cm, respectivamente. Tal redução reflete o maior impacto da cultura anual sobre a qualidade do solo (Doran et al., 1994).

A biomassa microbiana é muito sensível às alterações nas formas de carbono orgânico do solo em razão das mudanças no manejo ou uso do solo (Carter, 1986; Powlson et al., 1987). A pós a alteração ser introduzida, a biomassa microbiana sofre flutuações até atingir um novo equilíbrio.

O quadro 4 apresenta os valores da relação $\mathrm{C}_{\text {microbiando }} / \mathrm{C}_{\text {orgânico, expressa em percentagem, e }}$ mostra que a quantidade de $\mathrm{C}$ imobilizado como biomassa microbiana foi menor em A10. Nos demais usos do solo (MN, P20 e P25), a relação $C_{\text {microbiand }}$ $\mathrm{C}_{\text {orgânico }}$ foi superior a 1,3. I sto indica quea dinâmica da matéria orgânica em A10 é bem mais lenta que na mata natural e nas pastagens, com entradas bem menores de material orgânico, tanto na parte aérea como no sistema radicular.

Valores da relação $C_{\text {microbiand }} / C_{\text {orgânico }}$ menores do que 1,0 , tal como as encontradas no tratamento A10, foram observados por Geraldes et al. (1995) em pastagem com 15 anos em Latossolo Vermel hoAmarelo distrófico.

Segundo Wardle (1992), os valores de $C_{\text {microbiano }}$ nem sempre se relacionam com o $\mathrm{C}_{\text {orgânico }}$ do solo. No quadro 6, estão os valores das correlações entre $\mathrm{C}_{\text {microbiano }}$ e $\mathrm{C}_{\text {orgânico. }}$ Verifica-se que somente na profundidade de $0-10 \mathrm{~cm}$ houve correlação significativa a $5 \%$. Nas demais profundidades, o $\mathrm{C}_{\text {orgânico }}$ não se correlacionou com nenhum dos parâmetros estudados.

Quadro 4. Valores da relação $C_{\text {microbiano }} / C_{\text {orgânico' }}$ expressos em percentagem, em uma Terra Roxa Estruturada sob diferentes tipos de uso e em diferentes profundidades

\begin{tabular}{lccc}
\hline & \multicolumn{3}{c}{ Profundidade (cm) } \\
\cline { 2 - 4 } \multicolumn{1}{c}{ Uso do solo } & $\mathbf{0 - 1 0}$ & $\mathbf{1 0 - 2 0}$ & $\mathbf{2 0 - 3 0}$ \\
\hline Mata (natural) & 1,7 & 2,0 & 1,9 \\
Pastagem (20 anos) & 1,5 & 1,3 & 1,5 \\
Pastagem (25 anos) & 2,0 & 2,6 & 2,5 \\
Algodão (10 anos) & 0,8 & 0,7 & 0,8 \\
\hline
\end{tabular}

Atividade enzimática - Observaram-se reduções na atividade enzimática em relação à mata natural somente para amilase. A área sob cultivo com al godoei ro por 10 anos apresentou atividade de amilase 81, 64 e 54\% menor, em relação à $M N$, para as profundidades de 0-10, $10-20$ e $20-30 \mathrm{~cm}$, respectivamente (Quadro 5). Esses dados indicam que, com o cultivo anual, o solo pode apresentar menor quantidade de carbono na forma de amido, dada a maior biossíntese da enzima.

A redução na atividade de amilase do solo com o cultivo também foi observada por Mohanty \& Padhan (1992), que concluíram ser a atividade enzimática um indicador sensível às mudanças de manejo do solo.

Com relação às pastagens, somente em P20 ena camada de $0-10 \mathrm{~cm}$ a atividade de amilase foi menor (36\%) em relação à $M N$.

A enzima celulase $\mathrm{P} 25$ apresentou atividades 47 e $74 \%$ maiores em comparação à $\mathrm{MN}$, para as profundidades de 0-10 e 10-20 cm, respectivamente, sugerindo entrada de substrato enriquecido em celul ose no agrossistema, causando síntese de novas moléculas de celulase.

As diferenças de atividade de amilase e celulase em P20 e P25, descritas anteriormente, parecem estar relacionadas com o tipo de gramínea cultivada. Em P20, o Panicum maximum e, em P25, a Brachiaria decumbens.

Quadro 5. Atividades de celulase e amilase em amostras de uma Terra Roxa Estruturada sob diferentes tipos de uso e em diferentes profundidades

\begin{tabular}{|c|c|c|c|}
\hline \multirow{2}{*}{ Uso do solo } & \multicolumn{3}{|c|}{ Profundidade $(\mathrm{cm})$} \\
\hline & 0-10 & $10-20$ & 20-30 \\
\hline & \multicolumn{3}{|c|}{ Celulase $\left(\mu g^{-1} h^{-1}\right.$ de AR na TFSE) } \\
\hline $\begin{array}{l}\text { Mata (natural) } \\
\text { Pastagem ( } 20 \text { anos) } \\
\text { Pastagem ( } 25 \text { anos) } \\
\text { Algodão (10 anos) }\end{array}$ & $\begin{array}{l}\text { 2,64 } \mathrm{Abc} \\
3,47 \mathrm{Aab} \\
3,87 \mathrm{Aa} \\
1,58 \mathrm{Ac}\end{array}$ & $\begin{array}{l}2,19 \mathrm{Ab} \\
2,77 \mathrm{Abab} \\
3,80 \mathrm{Aa} \\
1,84 \mathrm{Ab}\end{array}$ & $\begin{array}{l}2,84 \mathrm{Aab} \\
2,25 \mathrm{Bb} \\
3,36 \mathrm{Aa} \\
2,08 \mathrm{Ab}\end{array}$ \\
\hline \multirow[t]{2}{*}{ C.V. $(\%)^{(1)}$} & \multicolumn{2}{|c|}{$\operatorname{Trat}^{(2)}=22,6 \quad$ Pro } & $=13)=19,2$ \\
\hline & \multicolumn{3}{|c|}{ Amilase $\left(\mu g g^{-1} h^{-1}\right.$ de AR na TFSA) } \\
\hline $\begin{array}{l}\text { Mata (natural) } \\
\text { Pastagem (20 anos) } \\
\text { Pastagem (25 anos) } \\
\text { Algodão (10 anos) }\end{array}$ & $\begin{array}{l}31,87 \mathrm{Aa} \\
20,40 \mathrm{Ab} \\
28,48 \mathrm{Aab} \\
5,91 \mathrm{AC}\end{array}$ & $\begin{array}{l}21,01 \mathrm{Bab} \\
18,02 \mathrm{ABb} \\
27,12 \mathrm{Aa} \\
7,63 \mathrm{Ac}\end{array}$ & $\begin{array}{l}16,83 \mathrm{Bab} \\
11,24 \mathrm{Bbc} \\
23,11 \mathrm{Aa} \\
7,69 \mathrm{Ac}\end{array}$ \\
\hline C.V. (\%) & \multicolumn{2}{|c|}{ Trat $=24,6$} & $=23,1$ \\
\hline
\end{tabular}

(1) Coeficiente de variação. ${ }^{(2)}$ Tratamento. ${ }^{(3)}$ Profundidade. AR açúcares redutores; TFSE - terra fina seca em estufa; TFSA terra fina seca ao ar; médias seguidas pela mesma letra não diferem pelo teste de Tukey a 5\%; letras minúsculas comparam médias na vertical; letras maiúsculas comparam médias na horizontal. 


\section{Quadro 6. Coeficientes de correlação simples entre $\mathrm{C}_{\text {orgânico, }} \mathrm{C}_{\text {microbiano }} \mathrm{e}$ atividades de celulase $\mathrm{e}$ de amilase em Terra Roxa Estruturada}

\begin{tabular}{|c|c|c|c|}
\hline & $\mathrm{C}_{\text {orgânico }}$ & $\mathrm{C}_{\text {Microbiano }}$ & Celulase \\
\hline \multicolumn{4}{|c|}{ Profundidade de $0-10 \mathrm{~cm}$} \\
\hline $\begin{array}{l}\mathrm{C}_{\text {microbiano }} \\
\text { Celulase }\end{array}$ & $\begin{array}{l}0,67^{*} \\
0,42^{\text {ns }}\end{array}$ & $0,67 *$ & \\
\hline Amilase & $0,70^{* *}$ & $0,73^{* *}$ & $0,60 *$ \\
\hline \multicolumn{4}{|c|}{ Profundidade de $10-20 \mathrm{~cm}$} \\
\hline $\begin{array}{l}\mathrm{C}_{\text {microbiano }} \\
\text { Celulase } \\
\text { Amilase }\end{array}$ & $\begin{array}{c}-0,19^{\text {ns }} \\
-0,30^{\text {ns }} \\
0,02^{\text {ns }}\end{array}$ & $\begin{array}{l}0,68^{*} \\
0,82^{* *}\end{array}$ & $0,65^{*}$ \\
\hline \multicolumn{4}{|c|}{ Profundidade de $20-30 \mathrm{~cm}$} \\
\hline $\begin{array}{l}\mathrm{C}_{\text {microbiano }} \\
\text { Celulase } \\
\text { Amilase }\end{array}$ & $\begin{array}{c}0,30^{\text {ns }} \\
-0,14^{\text {ns }} \\
-0,08^{\text {ns }}\end{array}$ & $\begin{array}{l}0,53^{*} \\
0,68^{*}\end{array}$ & $0,85^{* *}$ \\
\hline
\end{tabular}

*, ** significativo a 5 e 1\%, respectivamente; ${ }^{\text {ns }}$ não-significativo.

Segundo Andrade (1998), na rizosfera ocorrem vários tipos de interações de diferentes níveis de complexidade, eos microrganismos que vivem neste sistema são estimulados pela presença das raízes e desempenham papel muito importante, tanto em sistemas naturais quanto agrícolas, já que participam ativamente dos ciclos bi ogeoquímicos dos nutrientes.

Considerando a alta densidade de radicelas nas gramíneas, acredita-se que as diferenças nas atividades de celulase eamilase em P20 eP25 sejam reflexo da espécie de gramínea instalada. Todavia, de modo geral, as atividades das enzimas nas pastagens tenderam a ser semelhantes às da mata natural, enquanto a atividade da amilase em A10 foi significativamente menor do que a de MN .

Verifica-se, por meio dos resultados contidos no quadro 6 , que o $\mathrm{C}_{\text {microbiano }}$ correlacionou-se positivamentecom as atividade decelulasee amilase nas três profundidades de amostragens, indicando que a biomassa microbiana apresentou-se ativa em todas as profundidades analisadas e em todas as áreas, embora A10 tenha apresentado menos $\mathrm{C}_{\text {microbiano. }}$ Por outro lado, a atividade de amilase foi o parâmetro que mel hor relacionou com o $\mathrm{C}_{\text {microbiano. }}$

Kumari \& Singaram (1995) observaram que as atividades dessas enzimas, amilase ecelulase, dentre outras, relacionaram-se com a fertilidade do solo e quemai ores produções de biomassa correl acionaramse com o aumento na atividade enzimática, mostrando que o aumento da atividade das enzimas possivelmente seja devido ao aumento na mineralização de nutrientes pelos microrganismos do solo.

\section{CONCLUSÕES}

1. Os teores de $C_{\text {orgânico, }} \mathrm{C}_{\text {microbiano }}$ eas atividades de amilase e celulase foram semelhantes em solo sob mata natural e pastagens por 20 e 25 anos. Somente foi observada redução de $18 \%$ no $C_{\text {orgânico }}$ em pastagem por 25 anos em relaçãoà mata natural na profundidade de $0-10 \mathrm{~cm}$.

2. O cultivo convencional do algodoeiro por 10 anos provocou reduções de 54 a $81 \%$, em relação à mata natural no $\mathrm{C}_{\text {microbiano e na atividade da }}$ amilase nas três profundidades de amostragem, assim como apresentou val or da relação $C_{\text {microbiand }}$ Corgânico menor que 1,0, indicando redução na dinâmica da matéria orgânica do solo;

3. $\mathrm{O} \mathrm{C}_{\text {microbiano }}$ e as atividades de amilase e celulase correlacionaram-se positivamente nas três profundidades, enquanto o $C_{\text {orgânico correlacionou-se }}$ apenas com a atividade da amilase e $\mathrm{C}_{\text {microbiano }}$ na profundidade de $0-10 \mathrm{~cm}$.

4. A atividade de amilase foi o parâmetro que mel hor se correlacionou com o $\mathrm{C}_{\text {microbiano. }}$

\section{AGRADE CIM ENTOS}

À F undação de Amparo à Pesquisa do Estado de São Paulo (FAPESP), pelo apoio financeiro.

\section{LITE RATURA CITADA}

ANDRADE, G. Interações microbianas na rizosfera. In: FERTIBIO 98: REUNIÃO BRASILEIRA FERTILIDADE DO SOLO E NUTRIÇÃO DE PLANTAS, 23, REUNIÃO BRASILEIRA SOBRE MICORRIZAS, 7, SIMPÓSIO BRASILEIRO DE MICROBIOLOGIA DO SOLO, 5, REUNIÃO BRASILEIRA DE BIOLOGIA DO SOLO, 2, 1998, Caxambu. Resumos... Lavras, UFLA/SBCS/SBM, 1998. p.13.

ANDERSON, T.H. \& DOMSCH, K.H. Ratios of microbial biomass carbon to total organic in arable soils. Soil Biol. Biochem., 21:471-479, 1989.

ANGERS, D.A.; BISSONNETTE, N.; LÉGÈRE, A. \& SAMSON, $\mathrm{N}$. Microbial and biochemical changes induced by rotation and tillage in a soil under barley production. Can. J . Soil. Sci., 73:39-50, 1993.

CAMPBELL, C.A.; MOULIN, A.P.; BOWREN, K.E.; J ANZEN, H.H.; TOWNLEY-SMITH, L.; BIEDERBECK, V.O. Effect of crop rotations on microbial biomass, specific respiratory activity and mineralizable nitrogen in a Black Chernozenic soil. Can. J . Soil Sci., 72:417-427, 1992.

CARTER, M.R. Microbial biomass as an index for tillage-induced changes in soil biological properties. Soil Till. Res., 7:29-40, 1986. 
CERRI, C.C. Dinâmica da matéria orgânica em solos de pastagens. In: SIMPÓSIO SOBRE ECOSSITEMA DE PASTAGEM, J aboticabal, 1989. Anais. J aboticabal, FUNEP, UNESP, 1989. p.135-147.

CERRI, C.C.; VOLKOFF, B. \& EDUARDO, B.P. Efeito do desmatamento sobre a biomassa microbiana em latossolo amarelo da Amazônia. R. Bras. Ci. Solo, 9:1-4, 1985.

DABIN, B. Curso sobrematéria orgânica do sol o. Parte 1. Análise dos compostos húmicos do solo. Piracicaba, CENA, 1976. $115 p$.

DALAL, R.C. \& MAYER, R.J . Long-term trends in fertility of soils under continuous cultivation and cereal cropping in Southern Queesland. I. Overall changes in soil properties and trends in winter cereal yields. Aust. J . Soil Res., 24:265279, 1986a.

DALAL, R.C. \& MAYER, R.J . Long-term trends in fertility of soils under continuous cultivation and cereal cropping in Southern Queesland. II. Total organic and its rate of loss from the soil profile. Aust. J . Soil Res., 24:281-292, 1986b.

DORAN, J .W.; COLEMAN, D.C.; BEZDICEK, D.F. \& STEWART, B.A. Defining soil quality for a sustainable environment. Wisconsin, American Society of Agronomy, 1994.

GERALDES, A.P.A.; CERRI, C.C. \& FEIGL, B.J . Biomassa microbiana de solo sob pastagens na Amazônia. R. Bras. Ci. Solo, 19:55-60, 1995.

INSTITUTO AGRONÔMICO DE CAMPINAS - IAC. Recomendações de adubação e calagem para o estado de São Paulo. Campinas, 1996. 278p. (Boletim Técnico, 100).

J ENKINSON, D.S. \& LADD, J.N. Microbial biomass in soil: Measurement and turnover. In: PAUL, E.A. \& LADD, J .N. eds. Soil biochemistry. New York, Marcel Dekker, 1981. p.415-471.

J ENKINSON, D.S. \& RAYNER, J .H. Theturnover of soil organic matter in some of the Rothamsted Classical Experiments. Soil Sci., 123:298-305, 1977.
KUMARI, K.K. \& SINGARAM, P. Relationship among soil chemical, biochemical properties and enzyme activities. Madras Agric. J ., 82:69-70, 1995.

MOHANTY, R.K. \& PADHAN, S. Comparative studies on soil enzyme activities under two types of crops and adjacent grassland vegetation. Tropic. E col., 33:205-213, 1992.

PANCHOLY, S.K. \& RICE, E.L. Soil enzymes in relation field succession: amylase, cellulase, invertase, dehydrogenase and urease. Soil Sci. Soc. Am. Proc., 37:47-50, 1973.

POWLSON, D.S.; BROOKES, P.C. \& CHRISTESEN, B.T. Measurement of soil microbial biomass provides an early indication of changes in total soil organic matter due to straw incorporation. Soil Biol. Biochem., 19:159-164, 1987.

RIFFALDI, R.; SAVIOZZI , A.; LEVI-MINZI, R. \& MENCHETTI, $F$. Chemical characteristics of soil after 40 years of continuous maizecultivation. Agr. Ecosys. Environ., 49:239245, 1994.

ROSS, D.J . A seasonal study of oxygen uptake of some pasture soils and actives of enzymes hydrolysing sucrose and starch. J. Soil Sci., 16:73-85, 1965.

STEVENSON, F.J. Humus chemistry, genesis, composition, reaction. New York, J ohn Wiley \& Sons, 1982. 443p.

STEVENSON, F.J . Cycles of soil-carbon, nitrogen, phosphorus, sulphur and micronutrientes. New York, J ohn Wiley \& Sons, 1986. 380p.

TEIXEIRA, L.B. \& BASTOS, J.B. Matéria orgânica nos ecossistemas de floresta primária e pastagens na amazônia central. Belém, EMBRAPA-CPATU, 1989. 26p. (Boletim de Pesquisa, 99)

VANCE, E.D.; BROOKES, P.C. \& JENKINSON, D.S. An extraction method for measuring soil microbial biomass C. Soil Biol. Biochem., 19:703-707, 1987.

WARDLE, D.A. A comparative assessment of factors which influence microbial biomass carbon and nitrogen levels in soil. Biol. Rev., 67:321-358, 1992. 